\title{
Triplet Energy Management Between Two Signaling Units Through Cooperative Rigid Scaffolds
}

\author{
Paula Miro, Ignacio Vayá, Germán Sastre, M. Consuelo Jiménez, M. Luisa Marin and Miguel A. \\ Miranda*
}

\begin{abstract}
Through-bond triplet exciplex formation in donor-acceptor systems linked through a rigid bile acid scaffold has been demonstrated on the basis of kinetic evidence upon population of the triplet acceptors (naphthalene, or biphenyl) by through-bond triplet-triplet energy transfer from benzophenone.
\end{abstract}

Energy and electron transfer (ET and et, respectively) are two general non-radiative pathways in the quenching of a triplet excited state, ${ }^{1}$ which require effective orbital overlap within the van der Waals radii of donor (D) and acceptor (A) chromophores. ${ }^{2}$ Actually, it is well established that $k_{E T}$ drops to negligible small values when the $\mathrm{D}$-A distance is longer than 5-10 $\AA^{1}{ }^{1}$ When $\mathrm{D}$ and $\mathrm{A}$ are linked by a spacer, triplet-triplet energy transfer (TTET) could proceed through-space or through-bond (TB) mechanisms depending on the nature of the bridge. In flexible bridge-linked D-A systems, a rapid conformational equilibrium leads to spatial arrangements, in which the two chromophores are close enough for orbital overlap within the lifetime of the donor triplet, so that TTET happens through-space. ${ }^{3-11}$ Conversely, in the case of rigid saturated hydrocarbon bridges, in which D and A distances are substantially longer than the sum of the van der Waals radii, TB mechanism is largely predominating. ${ }^{12-21}$ In these systems, the observed TTET happening TB is facilitated by the $\sigma$ and $\sigma^{*}$ orbitals of the bridge and, in general, is strongly dependent on the conformations. ${ }^{22-24}$

Exciplex formation constitutes an alternative channel for excited states deactivation, ${ }^{1}$ whose involvement has been reported in the intramolecular singlet quenching of flexible systems., ${ }^{3,425-28}$ Interestingly, several examples have been reported, in which photoinduced electron transfer in D-A systems linked through a rigid bridge leads to 'exciplex' type fluorescence, more appropriately referred to as extended charge separated state. ${ }^{29-35}$ Moreover, triplet exciplex formation has been investigated in flexible benzophenone (BZP)/naphthalene (NPT) bichromophoric systems, in which decay of ${ }^{3} \mathrm{NPT}^{*}$ occurs through intramolecular exciplex formation with ground state $\mathrm{BZP} .^{36-38}$

To our knowledge, the possibility of TB triplet exciplex (TBTEX) formation in D-A systems linked through a rigid bridge has not yet been explored. Herein, this issue has been addressed by means of a novel approach based on a 'tandem' TB-TTET with subsequent formation of a TB extended exciplex from the triplet

Departamento de Química/Instituto de Tecnología Química UPV-CSIC, Universitat Politècnica de València, Camino de Vera $s / n, 46022$ Valencia, Spain Electronic Supplementary Information (ESI) available: Synthesis, exact mass and spectroscopic characterization $\left({ }^{1} \mathrm{H},{ }^{13} \mathrm{C}\right.$ and DEPT-NMR) of all compounds as well as additional steady-state, transient absorption spectra and computational methods. See DOI: 10.1039/x0xx00000x acceptor. The structural design of the newly synthesized D-A systems (1a,b and 2a,b, Figure 1) includes a rigid hydrocarbon skeleton provided by the natural lithocholic acid (LA) that exhibits an unusual cis fusion between rings $\mathrm{A}$ and $\mathrm{B}$ and has a carboxylic acid moiety at the lateral chain that allows covalent linking of the acceptor chromophores. The $\mathrm{D}$ is attached at $\mathrm{C}-3$ on the $\alpha$ or $\beta$ face of the skeleton to analyze the influence of the stereochemistry on the kinetics of the processes. The selected chromophores, BZP as D and NPT or biphenyl (BIP) as A, fulfill the following requirements: i) selective excitation of BZP is possible at $355 \mathrm{~nm}$; ii) the intersystem crossing quantum yield of BZP is very high ( $c a .1)$; iii) the triplet energies of NPT $(60.9 \mathrm{kcal} / \mathrm{mol})$ or BIP $(65.4 \mathrm{kcal} / \mathrm{mol})$ are lower than that of BZP $(68.6 \mathrm{kcal} / \mathrm{mol}),{ }^{39}$ thus the exergonicity of the ET process is guaranteed; iv) ${ }^{3} \mathrm{BZP} *$ has phosphorescence emission as well as transient absorption bands different from those of ${ }^{3} \mathrm{NPT}^{*}$ or ${ }^{3}$ BIP*. As a matter of fact, kinetic evidence obtained by laser flash photolysis (LFP) in solution, at room temperature, demonstrates the involvement of TB-TEX in the triplet decay of the NPT and BIP units in the selected systems $\mathbf{1 a}, \mathbf{b}$ and $\mathbf{2 a}, \mathbf{b}$.

Compounds 1a,b and 2a,b (Figure 1) were obtained as shown in detail in the Electronic Supplementary Information (ESI). The UVVis absorption spectra of $\mathbf{1 a}, \mathbf{b}$ and $\mathbf{2 a}, \mathbf{b}$ matched with the sum of the absorption spectra of the isolated chromophores $\mathbf{3 a}, \mathbf{b}+\mathbf{4}$ or $\mathbf{3 a}, \mathbf{b}+\mathbf{5}$ (Figure $\mathrm{S} 1$ in the ESI); the same was true for $\mathbf{6}$ and 7, lacking the LA spacer. These observations indicate the absence of significant ground state interactions between the donor and acceptor units.

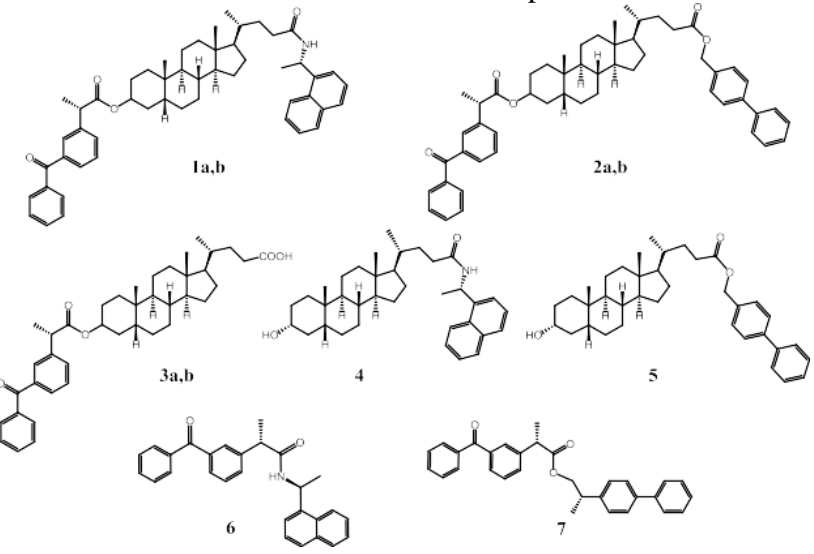

Fig. 1 Chemical structures of the synthesized D-A systems and control compounds. In 1 3, "a" stands for the $3 \alpha$ - and " $b$ " for the $3 \beta$-epimers.

The phosphorescence spectra of $\mathbf{1 a}$ and $\mathbf{1 b}$ in ethanol at $77 \mathrm{~K}$ upon BZP excitation at $355 \mathrm{~nm}$ were coincident with that of $\mathbf{3 a}$ 
(Figure 2, left), indicating that TB-TTET is completely prevented in the matrix when the chromophores are separated by the LA spacer. By contrast, when BZP and NPT were directly connected through an amide bond in compound $\mathbf{6}$ the phosphorescence arose exclusively from the NPT moiety, demonstrating that TTET within this D-A system is associated with clear phosphorescence spectral changes. The lack of TB-TTET in the matrix may be due to the predominance of frozen inefficient conformations of $\mathbf{1 a}, \mathbf{b}$.

A parallel series of experiments where the NPT unit was replaced with BIP were performed. The smaller BZP/BIP triplet energy gap in $\mathbf{2 a , b}$ was expected to result in a slower TTET process and therefore in a broader dynamic range. In fact, the phosphorescence spectra of $\mathbf{2 a , b}$ in ethanol matrix, after selective excitation at $355 \mathrm{~nm}$ showed exclusively the typical BZP emission, indicating that TB-TTET is again blocked in the frozen matrix. With this D-A combination, even the directly connected system 7 showed incomplete TTET, as revealed by spectral changes, which were in agreement with partial emission from the BIP unit (Figure 2, right).

To enhance the prospects of TB-TTET, the systems were investigated in solution at room temperature. Thus, LFP of 1a with selective excitation of BZP at $355 \mathrm{~nm}$, gave rise to transient absorption spectra where contribution of the BZP triplet excited state $\left({ }^{3} \mathrm{BZP} *, \lambda_{\max } c a .530 \mathrm{~nm}\right)$ was almost negligible, yet ${ }^{3} \mathrm{NPT}^{*}\left(\lambda_{\max }=\right.$ $420 \mathrm{~nm}$ ) was the predominating species as early as $20 \mathrm{~ns}$ after the laser pulse (Figure 3, left). This indicates a very fast TB-TTET from BZP to NPT in this system. However, a markedly different result was obtained for the $\beta$-epimer $\mathbf{1 b}$ (Figure S2A in the ESI), where the $530 \mathrm{~nm}$ centered band due to ${ }^{3} \mathrm{BZP}^{*}$ was clearly observed in the submicrosecond range. Nevertheless, at longer delays, the ${ }^{3} \mathrm{BZP} *$ contribution to the overall spectra decreased, and the band due to ${ }^{3} \mathrm{NPT}^{*}$ at $420 \mathrm{~nm}$ dominated the spectrum. Control experiments performed under the same conditions showed that an intermolecular 1:1 mixture of 3a and $\mathbf{4}$ exhibited after $60 \mathrm{~ns}$ the ${ }^{3} \mathrm{BZP} *$ band, which was not even detected for the directly linked system 6 immediately after the laser pulse (Figure S3 in the ESI). The TB-TTET process can be analyzed more accurately by looking at the kinetic traces monitored at $530 \mathrm{~nm}\left({ }^{3} \mathrm{BZP} *\right)$. Thus, it can be clearly observed in the inset of Figure 3, left that the process occurs instantaneously in the case of $\mathbf{1 a}$ and $\mathbf{6}$ (mostly during the laser pulse), is slower for $\mathbf{1 b}$ and takes even longer for the intermolecular situation $(\mathbf{3 a}+\mathbf{4})$. Accordingly, formation of ${ }^{3} \mathrm{NPT}^{*}$ (monitored through the growth at $420 \mathrm{~nm}$ ) was observed in the respective time windows. The BZP triplet lifetimes and TB-TTET rate constants are presented in Table 1.

The decay of the $420 \mathrm{~nm}$ band in $\mathbf{1 a}, \mathbf{b}$ should contain relevant information related to the possible involvement of an extended TBTEX from ${ }^{3} \mathrm{NPT}^{*}$. Thus, the kinetic traces monitored at $420 \mathrm{~nm}$ are shown in Figure 4, left, and the ${ }^{3} \mathrm{NPT}^{*}$ lifetimes, together with the TB-TEX rate constants, are given in Table 1 . The obtained results

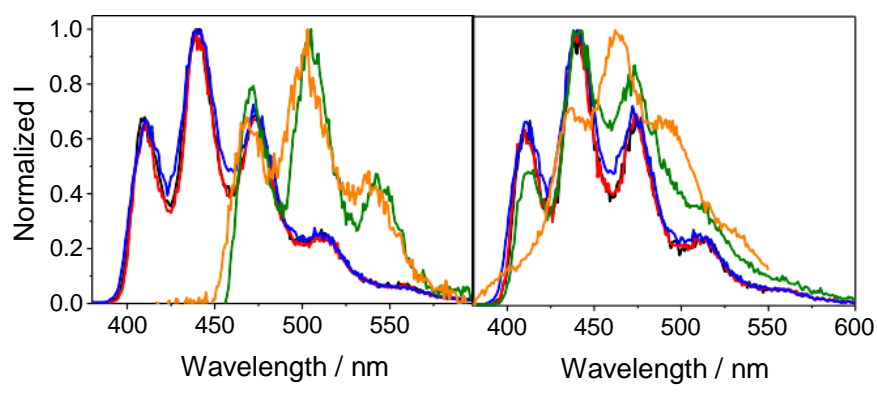

Fig. 2 Normalized phosphorescence spectra of left: 1a (black), 1b (red), 3a (blue), $\mathbf{4}$ (orange), and $\mathbf{6}$ (green), and right: 2a (black), 2b (red), 3a (blue), $\mathbf{7}$ (orange), and $\mathbf{5}$ (green) in ethanol matrix at $77 \mathrm{~K}$. The excitation wavelength was $355 \mathrm{~nm}$ in all cases except for $4(266 \mathrm{~nm})$ and $\mathbf{5}(285 \mathrm{~nm})$.

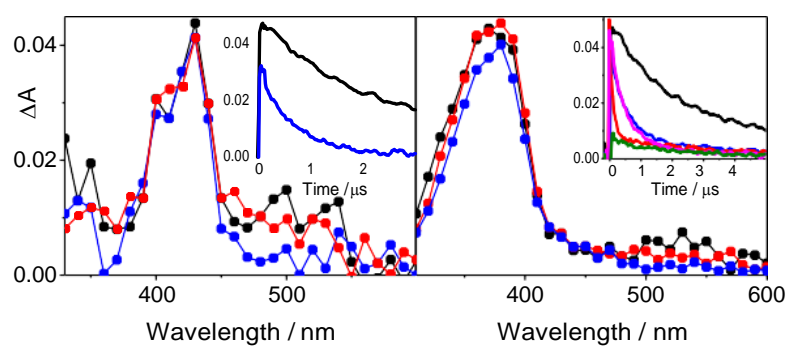

Fig. 3 Transient absorption spectra obtained upon LFP $\left(\lambda_{\text {exc }}=355 \mathrm{~nm}, \mathrm{CH}_{2} \mathrm{Cl}_{2}, \mathrm{~N}_{2}, \mathrm{~A}_{355}=\right.$ $0.2,5 \times 10^{-4} \mathrm{M}$ ) of left: $1 \mathrm{a}$ and right: $2 \mathrm{a}$ at $0.02 \mu \mathrm{s}$ (black), $0.2 \mu \mathrm{s}$ (red) and $1 \mu \mathrm{s}$ (blue) after the laser pulse. Insets show the decays of $\mathbf{1} \mathbf{a}$ or $\mathbf{2 a}$ (red), $\mathbf{1} \mathbf{b}$ or $\mathbf{2} \mathbf{b}$ (magenta), $\mathbf{3 a}$ or $\mathbf{3 b}$ (black), $\mathbf{3 a + 4}$ or $\mathbf{3 a + 5}$ at 1:1 molar ratio (blue) and $\mathbf{6}$ or $\mathbf{7}$ (green) monitored at $530 \mathrm{~nm}$.

demonstrate that extended TB-TEX formation is an efficient deactivation pathway for ${ }^{3} \mathrm{NPT}^{*}$ in the investigated linked systems 1a,b. The rate constant of this process was even higher than through space exciplex formation in $\mathbf{6}$, where the chromophores are directly linked. Interestingly, TB-TEX was faster for the $\beta$-epimer $\mathbf{1 b}$ than for its $\alpha$-analog 1a, in contrast to the tendency found in TB-TTET. As in the case of the NPT analogs, the TB-TTET process was also observed in the LFP experiments performed with 2a,b in solution (see transient absorption spectra in Figure 3, right as well as Figure $\mathrm{S} 2 \mathrm{~B}$ and controls in S4 in the ESI).

An important difference between 1a,b and 2a,b was found in the kinetics of ${ }^{3} \mathrm{BZP} *$ decay (Figure 3, insets), which was slower for the $\mathrm{BIP}$ derivatives, allowing for more accurate determination of the triplet lifetimes and rate constants (Table 1). The ${ }^{3} \mathrm{BZP} *$ lifetime of the $\beta$-derivative $\mathbf{2 b}$ was similar to that of the intermolecular $\mathbf{3 a}+\mathbf{5}$ mixture, and $c a$. 5 times longer than that of the $\alpha$-analog 2a; accordingly, the $k$ (TB-TTET) values were found to differ by one order of magnitude. As expected, when the two chromophores were directly connected (compound 7), TTET took place within the laser pulse.

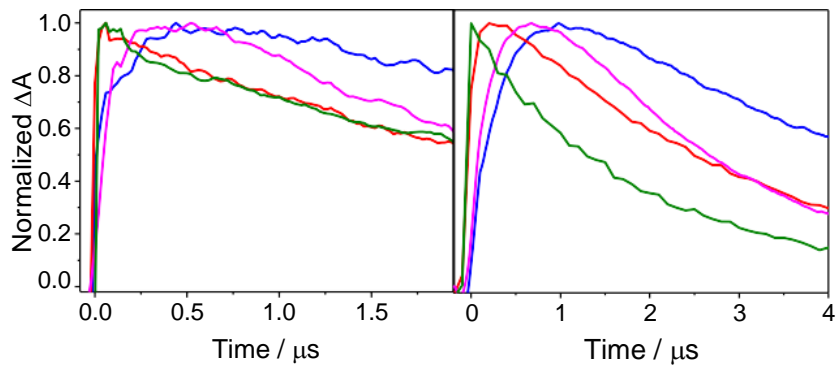

Fig. 4 LFP decays $\left(\lambda_{\text {exc }}=355 \mathrm{~nm}, \mathrm{CH}_{2} \mathrm{Cl}_{2}, \mathrm{~N}_{2}, \mathrm{~A}_{355}=0.2\right.$ ) of left: 1a (red), $\mathbf{1 b}$ (magenta), $\mathbf{3 a}+\mathbf{4}$ at 1:1 molar ratio (blue) and $\mathbf{6}$ (green) monitored at $420 \mathrm{~nm}$, and right: $\mathbf{2 a}$ (red), $\mathbf{2 b}$ (magenta), $3 \mathbf{a}+\mathbf{5}$ at 1:1 molar ratio (blue) and $\mathbf{7}$ (green) monitored at $380 \mathrm{~nm}$.

Table 1. Triplet lifetimes, TB-TTET and TB-TEX rate constants for BZP-NPT and BZP-BIP systems.

\begin{tabular}{|c|c|c|c|c|}
\hline System $^{a}$ & $\tau\left({ }^{3} \mathrm{BZP} *\right)^{b}$ & $k(\text { TB-TTET })^{\mathrm{c}}$ & $\begin{array}{c}\tau\left({ }^{3} \mathrm{NPT}^{*} \text { or }\right. \\
\left.{ }^{3} \mathrm{BIP}^{*}\right)^{\mathrm{b}}\end{array}$ & $k\left(\right.$ TB-TEX) ${ }^{c}$ \\
\hline $1 a$ & $<0.06$ & $>1.5 \times 10^{7}$ & 3.18 & $1.1 \times 10^{5}$ \\
\hline $1 b$ & 0.22 & $3.0 \times 10^{6}$ & 2.54 & $1.9 \times 10^{5}$ \\
\hline $2 a$ & 0.12 & $6.8 \times 10^{6}$ & 2.96 & $1.2 \times 10^{5}$ \\
\hline $2 b$ & 0.52 & $4.3 \times 10^{5}$ & 2.30 & $2.2 \times 10^{5}$ \\
\hline $3 a$ & 2.37 & N.A. & N.A. & N.A. \\
\hline $3 a+4^{d}$ & 0.65 & N.A. & 4.83 & N.A. \\
\hline $3 a+5^{d}$ & 0.67 & N.A. & 4.60 & N.A. \\
\hline 6 & $<0.01$ & $>1.0 \times 10^{8}$ & 3.81 & $5.5 \times 10^{4}$ \\
\hline 7 & $<0.02$ & $>4.8 \times 10^{7}$ & 1.91 & $3.1 \times 10^{5}$ \\
\hline
\end{tabular}

${ }^{a}$ In all cases, the concentration was $5 \times 10^{-4} \mathrm{M}$; ${ }^{\mathrm{b}}$ Units: $\mu \mathrm{s} ;{ }^{\mathrm{C}}$ Units: $\mathrm{s}^{-1}$ determined as $\left(1 / \tau-1 / \tau_{3 \mathbf{a}+4}\right)$ or $\left(1 / \tau-1 / \tau_{3 a+5}\right) ;{ }^{d}$ Each compound at $5 \times 10^{-4} \mathrm{M}$ concentration. 
More interestingly, analysis of the kinetic traces of the $380 \mathrm{~nm}$ band (Figure 4, right), allowed obtaining the ${ }^{3}$ BIP* lifetimes and the TB-TEX rate constants (Table 1), providing information concerning the involvement of the extended TB-TEX from ${ }^{3} \mathrm{BIP} *$. As a matter of fact, it can be observed that TB-TEX formation constitutes an efficient deactivation pathway for ${ }^{3} \mathrm{BIP} *$ in the LA-containing systems $\mathbf{2 a}, \mathbf{b}$, with rate constants in the same order than that of the through space process in 7. Also in this case, TB-TEX was slightly faster for the $\beta$-derivative $\mathbf{2 b}$ than for the $\alpha$-isomer $\mathbf{2 a}$. To rule out the possible involvement of a through-space mechanism, the chromophore-chromophore distances in compounds $\mathbf{2 a}$ and $\mathbf{2 b}$ have been investigated using molecular dynamics. Figure 5 shows that distribution of distances is centered at $c a$. 18 and $15 \AA$ for $\mathbf{2 a}$ and $\mathbf{2 b}$, respectively. Even more, conformations with intramolecular chromophore-chromophore distances $<10 \AA$ are very rare in both cases, with frequencies lower than $2 \%$.

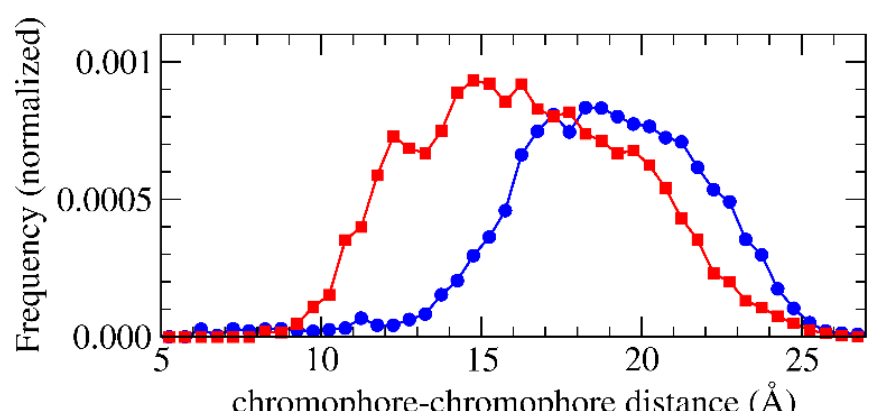

Fig. 5 Conformational landscape of molecules $\mathbf{2} \mathbf{a}$ and $\mathbf{2} \mathbf{b}$, based on the intramolecular chromophore-chromophore distance (as defined in Figure S5). The histograms have been produced from two molecular dynamics calculations of compounds $2 a$ (blue) and $\mathbf{2 b}$ (red) in dichloromethane at $300 \mathrm{~K}$.

In summary, the involvement of extended through-bond triplet exciplex formation in the excited state dynamics of naphthalene/benzophenone and biphenyl/benzophenone linked systems has been demonstrated by means of laser flash photolysis in solution, at room temperature. Kinetic evidence supporting this concept has been obtained from the decay of the naphthalene or biphenyl triplet after population via through-bond energy transfer from triplet benzophenone. All through-bond processes proceed across a rigid saturated bile acid scaffold and are strongly dependent on the relative spatial arrangement of the chromophores.

Financial support from the Spanish Government (Grants SEV2012-0267, CTQ2012-38754-C03-03, CTQ2013-47872-C2-1-P and JCI-2011-09926), EU (PCIG12GA-2012-334257), Generalitat Valenciana (Prometeo Program), and Technical University of Valencia (VLC/Campus, ASIC-UPV for computational facilities and Predoctoral FPI fellowship for P. Miro) is gratefully acknowledged.

\section{References}

1 N. J. Turro, V. Ramamurthy and J. C. Scaiano, Modern Molecular Photochemistry of Organic Molecules; University Science Books: New York, N.Y., 2010.

2 D. L. Dexter, J. Chem. Phys. 1953, 21, 836-850.

3 J. Jortner, M. Bixon, B. Wegewijs, J. W. Verhoeven and R. P. H. Rettschnick, Chem. Phys. Lett. 1993, 205, 451-455.

4 S. L. Zhang, M. J. Lang, S. Goodman, C. Durnell, V. Fidlar, G. R. Fleming and N. C. C. Yang, J. Am. Chem. Soc. 1996, 118, 9042-9051.

5 X. H. Xu, B. Chen, L. Z. Wu, L. P. Zhang and C. H. Tung, Arkivoc 2003, 182-190.
6 X.-H. Xu, X.-G. Fu, L.-Z. Wu, B. Chen, L.-P. Zhang, C.-H. Tung, H.-F. Ji, K. S. Schanze and R.-Q. Zhang, Chem. Eur. J 2006, 12, 5238-5245.

7 S.-M. Wang, M.-L. Yu, J. Ding, C.-H. Tung and L.-Z. Wu, J. Phys. Chem. A 2008, 112, 3865-3869.

8 L. Han, H. X. Wei, S. Y. Li, J. P. Chen, Y. Zeng, Y. Y. Li, Y. B. Han, Y. Li, S. Q. Wang and G. Q. Yang, Chemphyschem 2010, 11, 229-235.

9 W. G. McGimpsey, L. Chen, R. Carraway and W. N. Samaniego, J. Phys. Chem. A 1999, 103, 6082-6090.

10 W. G. McGimpsey, W. N. Samaniego, L. Chen and F. Wang, J. Phys. Chem. A 1998, 102, 8679-8689.

11 Z. Tan, R. Kote, W. N. Samaniego, S. J. Weininger and W. G. McGimpsey, J. Phys. Chem. A 1999, 103, 7612-7620.

12 M. R. Wasielewski, Chem. Rev. 1992, 92, 435-461.

13 D. Gust, T. A. Moore and A. L. Moore, Acc. Chem. Res. 1993, 26, 198-205.

14 D. Gust, T. A. Moore, A. L. Moore, C. Devadoss, P. A. Liddell, R. Hermant, R. A. Nieman, L. J. Demanche, J. M. Degraziano and I. Gouni, J. Am. Chem. Soc. 1992, 114, 3590-3603.

15 M. N. Paddon-Row, Acc. Chem. Res. 1982, 15, 245-251.

16 M. N. Paddon-Row, Acc. Chem. Res. 1994, 27, 18-25.

17 Y. Zhu and G. B. Schuster, J. Am. Chem. Soc. 1990, 112, $8583-$ 8585.

18 Y. Zhu and G. B. Schuster, J. Am. Chem. Soc. 1993, 115, 21902199.

19 C. H. Tung, L. P. Zhang, Y. Li, H. Cao and Y. Tanimoto, J. Phys. Chem. 1996, 100, 4480-4484.

20 C. H. Tung, L. P. Zhang, Y. Li, H. Cao and Y. Tanimoto, J. Am. Chem. Soc. 1997, 119, 5348-5354.

21 L. P. Zhang, B. Chen, L. Z. Wu, C. H. Tung, H. Cao and Y. Tanimoto, Chem. Eur. J 2003, 9, 2763-2769.

22 R. Hoffmann, Acc. Chem. Res. 1971, 4, 1-\&.

23 J. Kroon, A. M. Oliver, M. N. Paddon-Row and J. W. Verhoeven, J. Am. Chem. Soc. 1990, 112, 4868-4873.

24 K. D. Jordan and M. N. Paddon-Row, Chem. Rev. 1992, 92, 395410.

25 J. W. Verhoeven, Pure Appl. Chem. 1990, 62, 1585-1596.

26 J. W. Verhoeven, B. Wegewijs, T. Scherer, R. P. H. Rettschnick, J. M. Warman, W. Jager and S. Schneider, J. Phys. Org. Chem. 1996, 9, 387-397.

27 E. A. Khramtsova, V. F. Plyusnin, I. M. Magin, A. I. Kruppa, N. E. Polyakov, T. V. Leshina, E. Nuin, M. L. Marin and M. A. Miranda, J. Phys. Chem. B 2013, 117, 16206-16211.

28 I. Vaya, M. C. Jimenez and M. A. Miranda, J. Phys. Chem. B 2007, 111, 9363-9371.

29 H. Oevering, J. W. Verhoeven, M. N. Paddon-Row and J. M. Warman, Tetrahedron 1989, 45, 4751-4766.

30 M. R. Roest, A. M. Oliver, M. N. Paddon-Row and J. W. Verhoeven, J. Phys. Chem. A 1997, 101,4867-4871.

31 B. Wegewijs, R. M. Hermant, J. W. Verhoeven, M. P. Dehaas and J. M. Warman, Chem. Phys. Lett. 1990, 168, 185-190.

32 B. Wegewijs, A. K. F. Ng, R. P. H. Rettschnick and J. W. Verhoeven, Chem. Phys. Lett. 1992, 200, 357-363.

33 J. W. Verhoeven, Adv. Chem. Phys. 1999, 106, 603-644.

34 J. W. Verhoeven, T. Scherer and R. J. Willemse, Pure Appl. Chem. 1993, 65, 1717-1722.

35 H. Nagakubo, G. Kubota, K. Kubo, T. Kaneko, T. Sakurai and H. Inoue, Bull. Chem. Soc. Jpn. 1996, 69, 2603-2611.

36 M. C. Jimenez, S. E. Stiriba, R. Tormos, J. Perez-Prieto and M. A. Miranda, Photochem. Photobiol. Sci. 2004, 3, 36-38.

37 H. Shizuka, Pure Appl. Chem. 1997, 69, 825-830.

38 M. Yamaji, K. Okada, B. Marciniak and H. Shizuka, Chem. Phys. Lett. 1997, 277, 375-380.

39 M. Montalti, A. Credi, L. Prodi and M. T. Gandolfi, Handbook of Photochemistry; third ed., 2006. 